\section{References}

1. Bouzas B, Kilner PJ, Gatzoulis MA. Pulmonary regurgitation: not a benign lesion. Eur Heart J. 2005;26:433-9.

2. Abd El Rahman MY, Abdul-Khaliq H, Vogel M, Alexi-Meskishvili V, Gutberlet M, Lange PE. Relation between right ventricular enlargement, QRS duration, and right ventricular function in patients with tetralogy of Fallot and pulmonary regurgitation after surgical repair. Heart. 2000;84: 416-20.
3. Harrild DM, Berul CI, Cecchin F, Geva T, Gauvreau K, Pigula F, et al. Pulmonary valve replacement in tetralogy of Fallot: impact on survival and ventricular tachycardia. Circulation. 2009;119:445-51.

4. Dos L, Dadashev A, Tanous D, Ferreira-González IJ, Haberer K, Siu SC, et al. Pulmonary valve replacement in repaired tetralogy of Fallot: determinants of early postoperative adverse outcomes. J Thorac Cardiovasc Surg. 2009;138:553-9.

5. Bonhoeffer P, Boudjemline Y, Qureshi S, Le Bidois J, Iserin L, Acar P, et al. Percutaneous insertion of the pulmonary valve. J Am Coll Cardiol. 2002;39:1664-9.

\title{
Surgical pitfalls of excising an intramyocardial lipoma
}

\author{
Abdallah K. Alameddine, MD, Victor K. Alimov, MD, George S. Turner, Jr, CCP, and \\ David W. Deaton, MD, Springfield, Mass
}

This report highlights an extremely rare right atrial intramyocardial lipoma (RAIL) with surgically significant morphologic features in a transgender male patient. The tumor mass was generally encapsulated; however, the absence of a clear delineation between the tumor and the adjacent coronary artery led to an intraoperative reversible myocardial ischemia during surgical dissection. Furthermore, the tumor had a bosselated "diverticulum-like" inner cavity lined by myocardium, identifying it as a truly intramyocardial lipoma.

\section{CLINICAL SUMMARY}

A 21-year-old transgender man, genetically female on testosterone therapy for about a year and a half, presented with progressive onset of exertional dyspnea and dry cough. The chest radiograph showed a large mass around the right atrium, which was confirmed to be echogenic and located in the pericardial space. Heart function was normal. Evaluations by means of computed tomography and magnetic resonance imaging have demonstrated that the mass, which contained several thin septations, was consistent with lipoma. The mass occupied almost the entire free wall of the right atrium. The right coronary artery (RCA) appeared to be separate from the mass on the imaging studies. However, it was uncertain how much of the fatty tumor was epicardial, intramural, or endocardial.

From the Departments of Cardiac Surgery and Pathology, Baystate Medical Center, Springfield, Mass.

Disclosures: Authors have nothing to disclose with regard to commercial support.

Received for publication June 23, 2010; accepted for publication June 28, 2010; available ahead of print Aug 5, 2010.

Address for reprints: Abdallah K. Alameddine, MD, Departments of Cardiac Surgery and Pathology, Baystate Medical center, 759 Chestnut St, Springfield, MA 01199 (E-mail: akalameddine@gmail.com).

J Thorac Cardiovasc Surg 2011;141:592-4

$0022-5223 / \$ 36.00$

Copyright (c) 2011 by The American Association for Thoracic Surgery doi:10.1016/j.jtcvs.2010.06.043

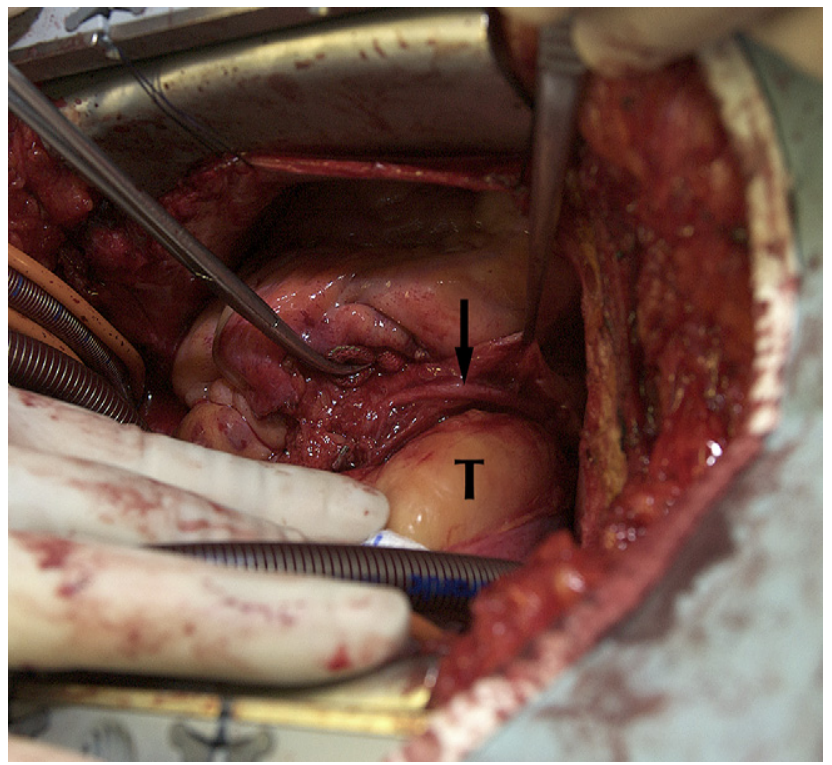

FIGURE 1. Right atrial mass $(T)$ as seen during surgical intervention. The black arrow indicates the right coronary artery.

Through a median sternotomy, the patient was started on moderate systemic hypothermic $\left(32^{\circ} \mathrm{C}\right)$ cardiopulmonary bypass with aortic and bicaval cannulation without aortic crossclamping. After the pericardium was opened, there was a large, yellowish rubbery mass $(15 \mathrm{~cm} \times 13 \mathrm{~cm} \times 6$ $\mathrm{cm})$ constituting part of the free wall of the right atrium. The tumor extended from the atrioventricular groove to the orifice of the coronary sinus and the anterior leaflet of the tricuspid valve anteriorly to the level of the crista terminalis laterally. Because of encasement into the tumor, the RCA had to be separated off the mass all the way to the crux of the heart at the inferior vena cava (Figure 1). At one point during this stage of dissection, inferior ventricular wall ischemia was evident by means of ST-segment elevation in lead II. The ischemic changes spontaneously 

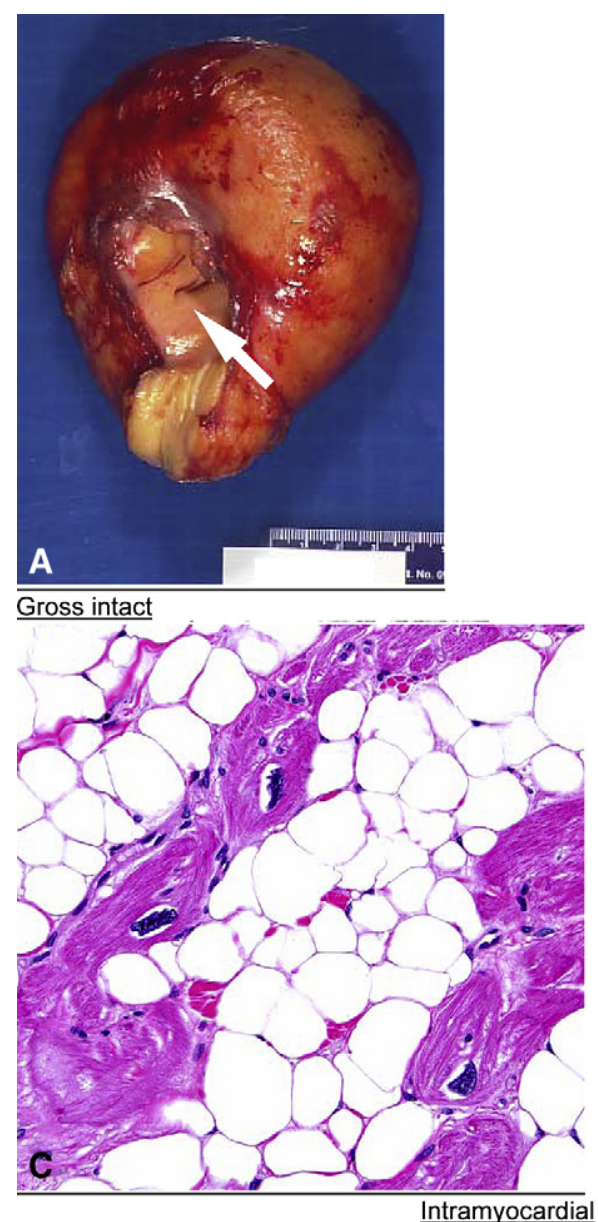
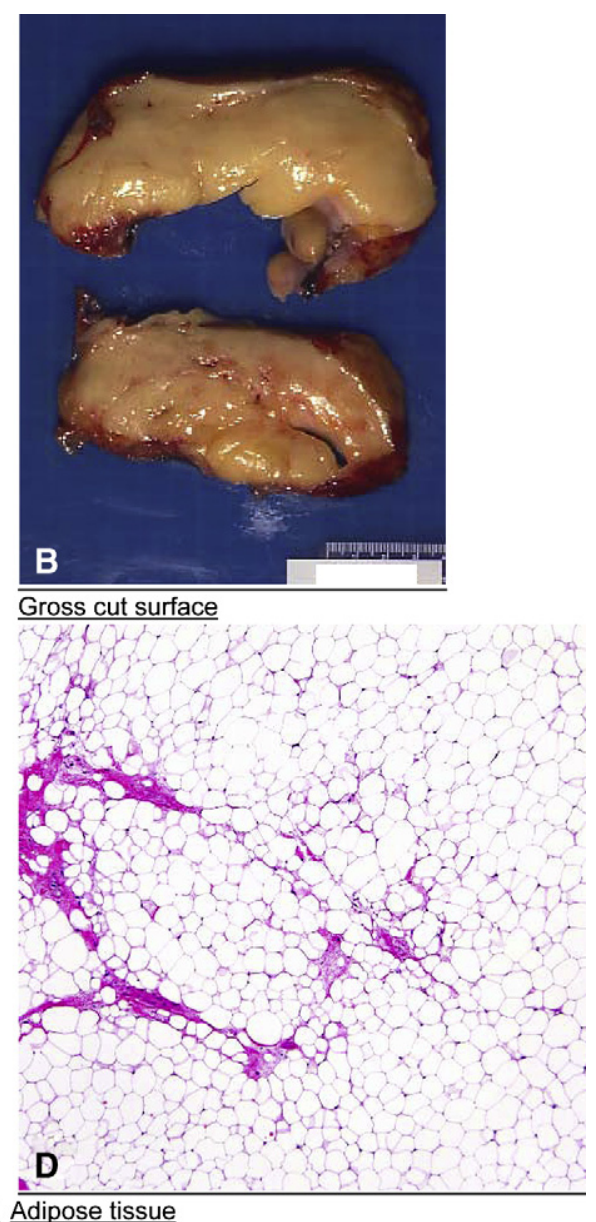

FIGURE 2. Surgical specimens (A and B): the white arrow indicates the osteum of the diverticulum. Histopathologically (C and D), there was no adipocytic or stromal nuclear atypia or hyperchromatism. Atypical stromal cells other than hypertrophic myocardial elements were not identified. Just focally, the lesion appears to be infiltrating cardiac muscle, but most of the lesion is devoid of any muscular component; it would generally be expected to see more diffuse/ infiltrative involvement of the cardiac muscle in lipomatous hypertrophy. Immunohistochemical studies were performed, and the results were as follows: desmin, positive in myocytes within the mature adipose tissue of the mass; myoglobin, positive in myocytes within the mature adipose tissue of the mass; myogenin, negative in myocytes within the mature adipose tissue of the mass; HMB-45, negative in stromal elements within mature adipose tissue; melan-A, negative in stromal elements within mature adipose tissue; estrogen receptor, negative in cellular elements of the tumor; and progesterone receptor, negative in cellular elements of the tumor.

recovered with release of the retraction of the RCA, which was necessary for better surgical exposure. Subsequently, nitroglycerin was administered and maintained throughout the procedure, halting the ischemic changes. After total tumor excision, the atrial defect was closed with a $4 \mathrm{~cm} \times 5$ $\mathrm{cm}$ patch of autologous pericardium.

The patient's recovery was uneventful. The resected specimen had a $4 \mathrm{~cm} \times 4 \mathrm{~cm}$ bosselated, "diverticulum-like," inner cavity that was lined by a glistening tan-white membrane. Histologically, the mass was lined by myocardium, which was positive for desmin and myoglobin, suggesting that the tumor had indeed originated within the atrial wall. The mass was comprised predominantly of mature adipose tissue of an intramyocardial lipoma (Figure 2). The receptors in cellular and stromal elements of this tumor were negative for estrogen and progesterone, respectively. After the oper- ation, the patient's condition improved, and he was well at the 6-month follow-up visit.

\section{DISCUSSION}

This case emphasizes the morphologic findings of true RAIL, an extremely rare cardiac tumor; before 1987, there were only 3 reported cases of RAIL in the Englishlanguage literature. ${ }^{1,2}$ Since that date, there have been similar cases reported, but they were predominately epicardial in location. Asymptomatic RAIL is regarded as a benign neoplasm. Symptoms are usually heralded by arrhythmias, obstructive symptoms, or pericardial effusion. In the present case atrial diverticulization of the tumor mass resulted in an inefficient atrial forward flow through the atrioventricular valve, with consequent clinically significant shortness of breath. 
The differential diagnosis includes liposarcomas and lipomatous hypertrophy of the interatrial septum, which both carry a different prognosis. Because of their tissue-infiltrative process, liposarcomas carry worse prognosis than lipomas. Lipomatous hypertrophy of the interatrial septum is generally considered a benign lesion, and surgical intervention might be required to control recalcitrant atrial arrhythmias. Magnetic resonance imaging has been shown to be superior to computed tomography in delineating the extent and location of lipoma. ${ }^{3,4}$ In our patient such ancillary tests failed to define the true anatomic margins between the RCA and the tumor; missing these anatomic attributes made surgical dissection unsafe because of possible damage to the RCA. Careful intraoperative visualization and protection of the adjoining coronary artery are mandatory to make the operation safer.

When symptoms are present, this case supports the recommendation for prompt surgical excision of these tumors, which has proved to be effective. Although preoperative serum-level evaluation of testosterone was not performed, we do not know for sure whether hyperandrogenization trophic effects of testosterone have played any role on lipoma formation.

We thank Dr Christopher Otis of the pathology department for his helpful comments.

\section{References}

1. McAllister HA, Fenoglio JJ. Tumors of the cardiovascular system. In: Atlas of tumor pathology, second series, fascicle 15. Washington, DC: Armed Forces Institute of Pathology; 1978. p. 44-6.

2. Mullen JC, Schipper SA, Sett SS, Trussler GA. Right atrial lipoma. Ann Thorac Surg. 1995;59:1239-40.

3. Araoz PA, Mulvagh SL, Tazelaar HD, Julsrud PR, Breen JF. CT and MRI imaging of benign primary cardiac neoplasms with echocardiographic correlation. Radiographics. 2000;20:1303-19.

4. Hananouchi GI, Goff WB. Cardiac lipoma: six-year follow-up with MRI characteristics, and a review of the literature. Magn Reson Imaging. 1990;8:825-8.

\title{
A simplified technique of full-thickness transabdominal laparoscopic repair of Morgagni hernia
}

\author{
Rajeev Pathak Misra, DO, ${ }^{a}$ and Jess D. Schwartz, MD, ${ }^{\mathrm{b}}$ Albuquerque, NM
}

Morgagni hernia (MH) represents less than $5 \%$ of all congenital diaphragmatic hernias. ${ }^{1}$ In adults, $\mathrm{MH}$ is usually symptomatic, with common symptoms, including pain in the chest or abdomen, obstruction, dysphagia, and rarely gastroesophageal reflux disease or bleeding. ${ }^{2}$ Predisposing conditions, such as chronic cough, constipation, trauma, pregnancy, and obesity, can contribute to the likelihood of symptomatic presentation. Repairs traditionally have been via laparotomy or thoracotomy; however, new technology has resulted in novel techniques for repair being reported, including thoracoscopic, laparoscopic, and even robotic repairs. ${ }^{2}$ Various strategies to deal with the hernia sac and close the defect have been described, and no consensus exists on whether to resect the sac or use prosthetic mesh. We report our experience of laparoscopic $\mathrm{MH}$ repair using

\footnotetext{
From the Division of General Surgery ${ }^{\mathrm{a}}$ and the Division of Cardiothoracic Surgery, ${ }^{\mathrm{b}}$ Department of Surgery, University of New Mexico Hospitals, Albuquerque, NM. Disclosures: Authors have nothing to disclose with regard to commercial support. Received for publication April 22, 2010; accepted for publication June 28, 2010.

Address for reprints: Jess Schwartz, MD, University of New Mexico, Department of Surgery, Division of General Surgery MSC 1, Albuquerque, NM 87131 (E-mail: jschwartz@salud.unm.edu).

J Thorac Cardiovasc Surg 2011;141:594-5

$0022-5223 / \$ 36.00$

Copyright (c) 2011 by The American Association for Thoracic Surgery doi:10.1016/j.jtcvs.2010.06.046
}

a simple technique of transabdominal wall suturing without the use of prosthetic mesh in 2 adult patients.

\section{CLINICAL SUMMARY Case 1}

A 50-year-old man whose chief symptom was intermittent dyspnea on exertion and epigastric pain with vomiting was found to have $\mathrm{MH}$ on chest $\mathrm{x}$-ray. The patient's body mass index was $35 \mathrm{~kg} / \mathrm{m}^{2}$. Computed tomography scan of the chest and abdomen showed a fat-containing MH without evidence of obstruction. Given the symptomatic nature of the hernia, elective laparoscopic repair was offered. The patient tolerated the procedure well and was discharged on postoperative day 3 , tolerating a regular diet. On follow-up at 6 and 18 months, the patient remained asymptomatic and there was no evidence of recurrence on computed tomography scan or upper gastrointestinal fluoroscopy.

\section{Case 2}

A 34-year-old developmentally delayed man underwent workup for recurrent episodes of dehydration and obstructive symptoms. Diagnosis of MH was confirmed by upper gastrointestinal fluoroscopy and computed tomography (Figure 1). The patient's body mass index was $18 \mathrm{~kg} / \mathrm{m}^{2}$. 